\section{BMJ Open Respiratory Research}

\title{
Clinical and financial burden of hospitalised community-acquired pneumonia in patients with selected underlying comorbidities in England
}

James Campling, ${ }_{1}^{1}$ Dylan Jones, ${ }^{2}$ James Chalmers, ${ }^{3}$ Qin Jiang, ${ }^{4}$ Andrew Vyse, ${ }^{1}$ Harish Madhava, ${ }^{1}$ Gillian Ellsbury, ${ }^{1}$ Adrian Rabe, ${ }^{5}$ Mary Slack ${ }^{6}$

\section{ABSTRACT}

Background Hospitalised pneumonia may have longterm clinical and financial impact in adult patients with underlying comorbidities.

Methods We conducted a retrospective cohort study using the Hospital Episode Statistics (HES) database to determine the clinical and financial burden over 3 years of hospitalised community-acquired pneumonia (CAP) to England's National Health Service (NHS). Subjects were adults with six underlying comorbidities (chronic heart disease (CHD); chronic kidney disease (CKD); chronic liver disease (CLD); chronic respiratory disease (CRD); diabetes mellitus (DM) and post bone marrow transplant (postBMT)) with an inpatient admission in 2012/2013. Patients with CAP in 2013/2014 were followed for 3 years and compared with similarly aged, propensity score-matched adults with the same comorbidity without CAP.

Findings The RR of hospital admissions increased after CAP, ranging from 1.08 (95\% $\mathrm{Cl} 1.04$ to 1.12) for CKD to 1.38 (95\% Cl 1.35 to 1.40$)$ for CRD. This increase was maintained for at least 2 years. Mean difference in hospital healthcare costs (£) was higher for CAP patients in 2013/2014; ranging from $£ 1115$ for DM to $£ 8444$ for BMT, and remained higher for $4 / 6$ groups for 2 more years, ranging from $£ 1907$ (95\% Cl $£ 1573$ to $£ 2240$ ) for DM to $£ 11167$ (95\% Cl £10 847 to £11 486) for CRD.) The OR for mortality was significantly higher for at least 3 years after $\mathrm{CAP}$, ranging from $4.76(95 \% \mathrm{Cl} 4.12$ to $5.51, \mathrm{p}<0.0001)$ for CLD to $7.50(95 \% \mathrm{Cl} 4.71$ to $11.92, \mathrm{p}<0.0001)$ for BMT. Interpretation For patients with selected underlying comorbidities, healthcare utilisation, costs and mortality increase for at least 3 years after being hospitalised CAP.

\section{INTRODUCTION}

Community acquired pneumonia (CAP) is a major cause of morbidity and mortality. ${ }^{1}$ Pneumonia has a considerable impact on the healthcare systems of the UK, being responsible for more hospital admissions and bed days than any other lung disease in the UK. ${ }^{1}$ Across Europe, annual inpatient care for pneumonia accounts for $€ 5.7$ billion of healthcare expenditure. ${ }^{1}$ Streptococcus pneumoniae remains the most commonly identified

\section{Key messages}

What is the key question?

-What is the clinical and financial burden to National Health Service (NHS) England for an episode of hospitalised community-acquired pneumonia (CAP) in patients with certain comorbidities?

What is the bottom line?

- In patients with certain comorbidities, an episode of hospitalised CAP results in an increase in the clinical and financial burden to NHS England for at least 3 years.

- Furthermore, the risk of death is significantly increased for at least 3 years.

Why read on?

- This study demonstrates the long-term impact of hospitalised CAP, both for individual patients with certain comorbidities and for the health service.

cause of CAP; however, the microbiological aetiology is not identified in approximately $50 \%$ of cases. ${ }^{2}{ }^{3}$ Hospitalised CAP carries a mortality rate of $5 \%$ to $15 \%$, rising to more than $30 \%$ for those admitted to intensive care,,$^{23}$ and results in 29000 deaths per annum in the UK. ${ }^{1}$ Traditionally, the clinical and economic costs of an episode of hospitalised CAP have been assumed to be shortlived, with patients subsequently returning to their previous health state. ${ }^{4}$ However, recent data challenge this assumption, with studies suggesting a long-term reduction in quality of life ${ }^{56}$ and decreased long-term survival in those with an underlying comorbidity who experience an episode of hospitalised pneumonia. Recognition of the long-term health consequences of CAP is important to inform secondary prevention strategies. It is well established that a myocardial infarction, while being a serious acute event, also carries a significant long-term morbidity in 

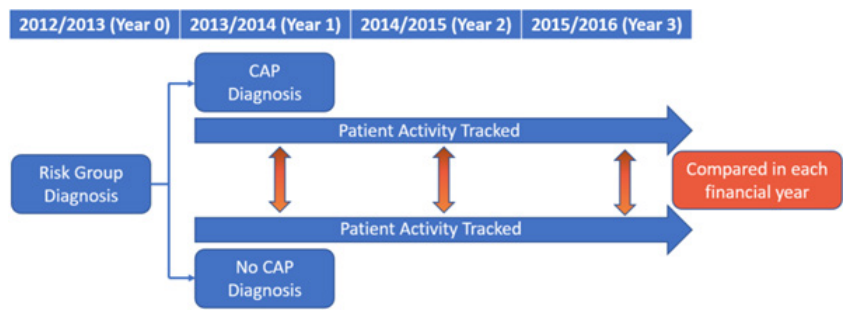

Figure 1 Study design. CAP, community-acquired pneumonia.

terms of direct and indirect health consequences, and increased mortality. ${ }^{7}$ Patients with myocardial infarction are therefore offered secondary prevention and rehabilitation, interventions that are proven to reduce long-term morbidity and mortality. Such interventions are not available for CAP, in part because the long-term health consequences of CAP, particularly in multimorbid patients, are less well described. We hypothesised that a diagnosis of hospitalised CAP in an individual with a specific comorbidity would have clinical and economic implications beyond the initial diagnosis.

\section{Aims of the study}

Between 2013/2014 and 2015/2016, this study investigated the extent of any additional healthcare resource utilisation, patient costs and in-hospital mortality for patients with comorbidities who had CAP as a complicating condition in 2013/2014.

\section{METHODS}

Study design

This was a retrospective cohort study using data from the Hospital Episode Statistics (HES) database (online supplemental box 1) between the financial years 2012/2013 and 2015/2016. Eligible patients were identified in 2012/2013 and those who met the study criteria were then followed for three subsequent years (2013/2014, 2014/2015 and 2015/2016) (figure 1).

Participants were aged 18+ years in 2012/2013 and consisted exclusively of patients with one or more of six comorbidities as denoted by the relevant International Statistical Classification of Diseases and Related Health Problems, Tenth revision (ICD-10) codes (online supplemental table 1) in either the primary or secondary position. ${ }^{89}$ The six comorbidities selected were: bone marrow transplant (BMT), chronic respiratory disease (CRD), diabetes, chronic kidney disease (CKD), chronic heart disease (CHD) and chronic liver disease (CLD). These were chosen because adults with these comorbidities are considered to be at an increased risk of pneumococcal disease. $^{10}$

None of the participants selected had evidence of a diagnosis of pneumonia (online supplemental table 1) in 2012/2013 and none had died during 2012/2013. The study group were those participants who were subsequently hospitalised with a diagnosis of CAP (based on the relevant ICD-10 codes) in 2013/2014. The comparison group were those participants with no diagnosis of hospitalised CAP in 2013/2014 and who were not hospitalised with CAP at any subsequent point during the study period.

It was possible for patients to have more than one of the selected comorbidities. The risk of developing CAP increases when patients have an increasing number of risk factors, a phenomenon known as 'risk stacking'. ${ }^{11}$ In order to correct for this confounder, we used the propensity scoring method ${ }^{12}$ to match each participant in the study group with a participant in the comparator group (1:1 ratio). It was also not possible to account for severity of the underlying comorbidity, due to limitations of the HES database. To counterbalance this, we incorporated healthcare utilisation within the base year (2012/2013) in the propensity score matching (PSM). PSM is a statistical technique in which the group of interest is matched for similarity with one or more controls. For each individual comorbidity, the propensity score was estimated utilising: age, sex, ethnicity, index of multiple deprivation, other comorbidities from the six comorbidities selected and healthcare utilisation within the baseline year (2012/2013). A study participant with a diagnosis of hospitalised CAP was matched with a comparator participant with the same comorbidity but with no diagnosis of hospitalised CAP in 2013/2014 (and was not hospitalised with CAP at any subsequent point during the study period).

Once matched, the study group and comparison group were followed over a 3-year period from 2013/2014 to 2015/2016 and assessed for differences in healthcare resource utilisation (overall hospital admissions, outpatient attendance and accident and emergency department (A\&E) visits), the associated hospital healthcare costs and mortality during each of the three study years. The objective was to investigate if, and to what extent, these outcome measurements differed in participants with comorbidities who were hospitalised with CAP in 2013/2014 compared with those with the same comorbidities who were not hospitalised with CAP (either in $2013 / 2014$ or the subsequent two study years).

\section{Inclusion/exclusion criteria}

Participants had to be aged 18+ years in 2012/2013 and for inclusion needed to have at least one of the defined comorbidities. Patients with a diagnosis of CAP (online supplemental table 1, ICD-10) or evidence of inpatient death during 2012/2013 were excluded. Those patients with a secondary pneumonia diagnosis after 48 hours of the primary admission were also excluded as this as was considered to reflect hospital-acquired pneumonia (HAP) rather than CAP. Patients with missing data (approximately $0.5 \%$ of all data in HES), where the admission/visit/attendance did not have a corresponding Healthcare Resource Groups (HRG) code were excluded because it was not possible to cost the 
associated admission/visit/attendance in the absence of an HRG code. HRGs are standard groupings of clinically similar treatments which use comparable levels of healthcare resource, including groups of ICD-10 diagnoses that have similar resource implications. Outpatient follow-up visits included regular and programmatic visits among all groups.

\section{Categorisation of CAP and non-CAP}

Within each individual risk population, subjects were categorised into two groups based on the presence or absence of a primary or secondary diagnosis code for CAP (online supplemental table 1, ICD-10) in 2013/2014. However, if any secondary pneumonia diagnosis occurred after 48 hours of the primary admission, this subject was excluded as it was considered to be a HAP. ${ }^{13}$ Subjects were included in the non-CAP comparison group if there was no diagnosis of pneumonia (online supplemental table 1: ICD-10) during the three study years (2013/14 to $2015 / 16)$.

\section{Outcome}

The three key outcomes examined during the period $2013 / 2014$ to $2015 / 2016$ were healthcare resource utilisation (total number of hospital admissions, total number of outpatient attendances and total number of A\&E visits), the costs associated with these activities and in-hospital mortality.

For each patient, the number of hospital admissions, outpatient attendances and A\&E visits were retrieved from the database according to the corresponding HRG. ${ }^{14}$ Hospitalised mortality was defined when hospital discharge status was 'death'.

The associated costs for each activity were then determined using the appropriate National Health Service (NHS) tariffs and reported in 2016 UK pounds sterling (£). Costs from earlier years were adjusted using the Hospital and Community Health Services (HCHS) index from the Personal Social Services Research Unit (PSSRU) ${ }^{15}$

\section{Statistical analysis}

Demographic characteristics were measured and summarised using means, medians, $\mathrm{SD}$, and $\mathrm{p}$ values where appropriate.

Healthcare resource utilisation reported as activity was analysed using a negative binomial model. Negative binomial modelling corrects for overdispersion of the data, which is useful for studies utilising large data sets, such as this one. The model was run for patients from each comorbidity category and the rate ratio (RR) for each category was compared with their propensity scorematched pairs, in each of the three study years, using CAP diagnosis as the dependent variable and each type of healthcare resource use (admissions, outpatient appointments or A\&E visits) as the outcome variable. The model was adjusted based on the recruitment of propensityscore matched patients for potential explanatory variables (age, gender, ethnicity, elective and non-elective admissions, conditions in the Charlson Comorbidity Index ${ }^{16}$ and the presence of diagnoses used to identify the other comorbidities at the point of participant selection in 2012/2013). These variables were selected based on likelihood ratios calculated from univariate logistic regression performed on each of them.

To determine the costs for each type of healthcare resource use as calculated through HRG tariffs, a generalised linear model was used. In this model, CAP diagnosis was the dependent variable, while costs were the outcome variable. Adjustments were made with the same factors based on likelihood ratios from univariate logistic regression performed on each of them. Mean differences for costs were then calculated (with 95\% CIs generated using the least squares method) between the study group and comparison group for each comorbidity, for each of the three study years individually and for all three study years collectively.

In both models statistical significance was considered achieved if the $95 \%$ CIs around the point estimate did not include $1(\mathrm{p}<0.05)$.

To investigate the effect of hospitalised CAP on subsequent in-hospital mortality, a conditional logistic regression model was used to reduce bias given that matched data were being used. In-hospital mortality was the dependent variable, while other variables (hospitalised CAP, age, gender, ethnicity, elective and non-elective admissions in at the point of selection in 2012/2013, conditions in the Charlson comorbidity index and presence of diagnoses used to identify the other comorbidities) were explanatory variables. ORs for mortality comparing the study group with the comparison group within each of the selected comorbidities were estimated with $95 \%$ CIs.

As the HES database includes all the data entered from the NHS in England, it is possible for implausible extreme values to be recorded in the database. For example, one individual was admitted to hospital, on average, every 1.5 days. To ensure this data did not skew the results to favour our hypothesis, the top 1 percentile of results were excluded from the analysis.

For quality control purposes, each query was validated by re-running the queries.

\section{Patient and public involvement}

Patients or the public were not involved in the design, or conduct, or reporting, or dissemination plans of our research.

\section{RESULTS}

A total of 2205850 candidate patients with one or more of the six comorbidities were identified in HES in 2012/2013. The total number of patients in each of the six comorbidities were as follows CHD $n=981397$; CKD $\mathrm{n}=232488$; CLD n=71261; CRD n=294283; diabetes 
$\mathrm{n}=621887$; and post-BMT $\mathrm{n}=4534$. After selecting only those who had a diagnosis of hospitalised CAP in 2013/2014 and a 1:1 propensity score-matched control, the number of patients in each group was: $\mathrm{CHD} n=36386$; CKD n=12190; CLD n=2222; CRD n=20 764; diabetes $\mathrm{n}=16382$; and post-BMT $\mathrm{n}=271$. (table 1 )

These formed the cohort that was investigated for healthcare resource utilisation, hospital admission costs and in-hospital mortality over the period 2013/2014 to 2015/2016.

\section{Healthcare resource utilisation}

For each of the three study years (2013/2014, 2014/2015 and 2015/2016), subsequent healthcare resource utilisation (overall hospital admissions, outpatient attendance and A\&E visits) for patients with each category of comorbidity who were hospitalised with CAP in 2013/2014 were compared with those for patients with the same category of comorbidity but who were not hospitalised with CAP in 2013/2014 (or any of the subsequent two study years). Results are presented as RRs for each category of comorbidity and each category of healthcare resource utilisation during each of the three individual study years (table 2) (figure 2).

A statistically significant increase in the rate of healthcare resource utilisation was observed for patients with CHD, CKD, CLD, CRD and diabetes who were hospitalised with an episode of CAP in 2013/2014 compared with those with CHD, CKD, CLD, CRD and diabetes who did not develop hospitalised CAP. This was observed for each of the three categories of healthcare resource utilisation during each of the three study years with RRs ranging from 1.08 (95\% CI 1.04 to 1.12) for overall hospital admissions for CKD patients during 2013/2014 to 1.42 (95\% CI 1.37 to 1.46) for overall hospital admissions for CRD patients during 2015/2016. For BMT patients who had an episode of CAP in 2013/2014, there was evidence of an increase in healthcare resource utilisation for outpatient attendance only during 2013/2014 (RR 1.16; 95\% CI 1.02 to 1.32). There was no evidence of a difference in any of the three categories of healthcare resource utilisation when comparing other BMT patients with a diagnosis of CAP in 2013/2014 to those without during any of the three study years (RRs ranged from 0.93 (95\% CI 0.71 to 1.13 ) for A\&E visits during 2013/2014 to 1.28 (95\% CI 0.96 to 1.71) for overall hospital admissions during 2015/2016).

\section{Hospital admission costs}

Table 3 shows the mean difference in hospital healthcare costs $(£)$ during the 3-year study period for patients with each comorbidity who developed hospitalised CAP in 2013/2014 compared with those who did not. Results are presented for each category of comorbidity, for each individual study year and overall for the combined 3-year duration of the study. During 2013/2014 and overall for the three study years collectively, the mean hospital healthcare costs were higher for patients with each of the six comorbidities who were hospitalised with CAP than for those with the same comorbidities who did not develop hospitalised CAP. During 2013/2014 the mean difference in cost ranged from an increase of 11115 for patients with diabetes to $£ 8444$ for patients with BMT who developed CAP in 2013/2014, while overall for the full 3-year study period, the mean difference in hospital healthcare costs ranged from an increase of $£ 1907$ for patients with diabetes who developed CAP in 2013/2014 to $£ 11167$ for those with CRD who developed CAP in 2013/2014. During 2014/2015 and 2015/2016, mean higher costs were also incurred for four of the six comorbidity categories who developed CAP in 2013/2014. Exceptions were CKD and diabetic patients where a hospitalisation with CAP in 2013/2014 resulted in lower mean hospital healthcare costs during 2014/2015 and 2015/2016, respectively.

\section{In-hospital mortality}

Patients with comorbidities who developed hospitalised CAP in 2013/2014 had substantially higher ORs for in-hospital mortality when compared with those with comorbidities who did not develop CAP. This extended to each category of comorbidity for each of the three study years. Results are presented in figure 3. The OR was particularly high for BMT patients (OR 7.50, 95\% CI 4.71 to $11.92, \mathrm{p}<0.0001)$. For the remaining categories of comorbidity, ORs ranged from 4.76 (95\% CI 4.12 to 5.51, $\mathrm{p}<0.0001)$ for CLD patients to 5.94 (95\% CI 5.65 to 6.24 , $\mathrm{p}<0.0001)$ for CRD patients.

\section{DISCUSSION}

This is a large study using a national data set reflecting the adult hospital population ( 75000 participants) in England with six comorbidities. This provided sufficient data to closely match participants in the study group with those in the comparator group. While there are shortcomings using HES epidemiologic studies, using HES can be informative. ${ }^{17-19}$

\section{Principal findings}

We previously reported the variation in the likelihood of hospitalisation for CAP among adults with six comorbidities in England..$^{20}$ The current analysis used the same data set to quantify the clinical and financial burden of hospitalised CAP in these patients over the same time period.

This study illustrates for the first time the increase in the rate of hospital admissions in patients with the six clinical comorbidities included following an episode of hospitalised CAP. This increase was statistically significant in all comorbidity categories apart from post-BMT and was maintained across all three study years. However, there is a lack of precision around point estimates for healthcare resource utilisation for post-BMT patients specifically due to the small number of these participants $(n=271)$. As expected, there was variation between the different 
Table 1 Demographics of matched participants in CAP/non-CAP groups for each of the six comorbidities

\begin{tabular}{|c|c|c|c|c|c|c|c|c|c|c|c|c|}
\hline \multirow[b]{2}{*}{ Demographics } & \multicolumn{2}{|l|}{ CHD } & \multicolumn{2}{|l|}{ CKD } & \multicolumn{2}{|l|}{ CLD } & \multicolumn{2}{|l|}{ CRD } & \multicolumn{2}{|l|}{ Diabetes } & \multicolumn{2}{|c|}{ Post-BMT } \\
\hline & CAP & $\begin{array}{l}\text { non- } \\
\text { CAP }\end{array}$ & CAP & $\begin{array}{l}\text { non- } \\
\text { CAP }\end{array}$ & CAP & non-CAP & CAP & non-CAP & CAP & non-CAP & CAP & non-CAP \\
\hline \multicolumn{13}{|l|}{ Participant } \\
\hline $\begin{array}{l}\text { All candidate } \\
\text { participants }\end{array}$ & 44215 & 937182 & 14428 & 218060 & 2604 & 68657 & 25500 & 268783 & 21222 & 600665 & 369 & 4165 \\
\hline 1:1 Matched & 36386 & 36386 & 12190 & 12190 & 2222 & 2222 & 20764 & 20764 & 16382 & 16382 & 271 & 271 \\
\hline \multicolumn{13}{|l|}{ Age } \\
\hline Mean & 79.1 & 79.5 & 78.8 & 79.2 & 62.1 & 61.8 & 75.0 & 75.3 & 74.9 & 75.3 & 53.9 & 54.6 \\
\hline Median & 81.0 & 81.0 & 81.0 & 82.0 & 63.0 & 62.0 & 77.0 & 77.0 & 77.0 & 77.0 & 56.0 & 56.0 \\
\hline \multicolumn{13}{|l|}{ Gender } \\
\hline Male & $\begin{array}{l}17432 \\
(47.9 \%)\end{array}$ & $\begin{array}{l}17524 \\
(48.2 \%)\end{array}$ & $\begin{array}{l}5791 \\
(47.5 \%)\end{array}$ & $\begin{array}{l}5892 \\
(48.3 \%)\end{array}$ & $\begin{array}{l}909 \\
(40.9 \%)\end{array}$ & $\begin{array}{l}975 \\
(43.9 \%)\end{array}$ & $\begin{array}{l}9944 \\
(47.9 \%)\end{array}$ & $\begin{array}{l}10040 \\
(48.4 \%)\end{array}$ & $\begin{array}{l}7600 \\
(46.4 \%)\end{array}$ & $\begin{array}{l}7930 \\
(48.4 \%)\end{array}$ & $\begin{array}{l}102 \\
(37.6 \%)\end{array}$ & $\begin{array}{l}117 \\
(43.2 \%)\end{array}$ \\
\hline \multicolumn{13}{|l|}{ Ethnicity } \\
\hline White & $\begin{array}{l}33128 \\
(91.0 \%)\end{array}$ & $\begin{array}{l}33210 \\
(91.3 \%)\end{array}$ & $\begin{array}{l}10773 \\
(88.4 \%)\end{array}$ & $\begin{array}{l}10795 \\
(88.6 \%)\end{array}$ & $\begin{array}{l}1936 \\
(87.1 \%)\end{array}$ & $\begin{array}{l}1933 \\
(87.0 \%)\end{array}$ & $\begin{array}{l}19327 \\
(93.1 \%)\end{array}$ & $\begin{array}{l}19479 \\
(93.8 \%)\end{array}$ & $\begin{array}{l}14007 \\
(85.5 \%)\end{array}$ & $\begin{array}{l}13960 \\
(85.2 \%)\end{array}$ & $\begin{array}{l}231 \\
(85.2 \%)\end{array}$ & $\begin{array}{l}239 \\
(88.2 \%)\end{array}$ \\
\hline Mixed & $\begin{array}{l}68 \\
(0.2 \%)\end{array}$ & $\begin{array}{l}79 \\
(0.2 \%)\end{array}$ & $\begin{array}{l}29 \\
(0.2 \%)\end{array}$ & $\begin{array}{l}28 \\
(0.2 \%)\end{array}$ & $\begin{array}{l}11 \\
(0.5 \%)\end{array}$ & $5(0.2 \%)$ & $34(0.2 \%)$ & $33(0.2 \%)$ & $54(0.3 \%)$ & $65(0.4 \%)$ & & \\
\hline Asian/Indian & $\begin{array}{l}1167 \\
(3.2 \%)\end{array}$ & $\begin{array}{l}969 \\
(2.7 \%)\end{array}$ & $\begin{array}{l}558 \\
(4.6 \%)\end{array}$ & $\begin{array}{l}502 \\
(4.1 \%)\end{array}$ & $\begin{array}{l}108 \\
(4.9 \%)\end{array}$ & $96(4.3 \%)$ & $462(2.2 \%)$ & $377(1.8 \%)$ & $\begin{array}{l}1095 \\
(6.7 \%)\end{array}$ & $\begin{array}{l}1011 \\
(6.2 \%)\end{array}$ & $\begin{array}{l}13 \\
(4.8 \%)\end{array}$ & $6(2.2 \%)$ \\
\hline $\begin{array}{l}\text { Black/African } \\
\text { origin }\end{array}$ & $\begin{array}{l}444 \\
(1.2 \%)\end{array}$ & $\begin{array}{l}456 \\
(1.3 \%)\end{array}$ & $\begin{array}{l}293 \\
(2.4 \%)\end{array}$ & $\begin{array}{l}260 \\
(2.1 \%)\end{array}$ & $\begin{array}{l}42 \\
(1.9 \%)\end{array}$ & $45(2.0 \%)$ & $147(0.7 \%)$ & $153(0.7 \%)$ & $435(2.7 \%)$ & $454(2.8 \%)$ & $5(1.8 \%)$ & 7 (2.6\%) \\
\hline Chinese & $\begin{array}{l}31 \\
(0.1 \%)\end{array}$ & $\begin{array}{l}22 \\
(0.1 \%)\end{array}$ & $\begin{array}{l}11 \\
(0.1 \%)\end{array}$ & $\begin{array}{l}19 \\
(0.2 \%)\end{array}$ & $3(0.1 \%)$ & $7(0.3 \%)$ & $12(0.1 \%)$ & $12(0.1 \%)$ & $23(0.1 \%)$ & $24(0.1 \%)$ & 0 & $1(0.4 \%)$ \\
\hline $\begin{array}{l}\text { Other/not } \\
\text { collected }\end{array}$ & $\begin{array}{l}1548 \\
(4.2 \%)\end{array}$ & $\begin{array}{l}1650 \\
(4.5 \%)\end{array}$ & $\begin{array}{l}526 \\
(4.3 \%)\end{array}$ & $\begin{array}{l}586 \\
(4.8 \%)\end{array}$ & $\begin{array}{l}122 \\
(5.5 \%)\end{array}$ & $\begin{array}{l}136 \\
(6.1 \%)\end{array}$ & $782(3.7 \%)$ & $710(3.5 \%)$ & 768 (4.7\%) & 868 (5.3\%) & $\begin{array}{l}22 \\
(8.1 \%)\end{array}$ & $18(6.6 \%)$ \\
\hline \multicolumn{13}{|l|}{$\begin{array}{l}\text { Index of } \\
\text { multiple } \\
\text { deprivation } \\
\text { (least to most) }\end{array}$} \\
\hline 0 to 20 & $\begin{array}{l}5693 \\
(15.6 \%)\end{array}$ & $\begin{array}{l}6238 \\
(17.2 \%)\end{array}$ & $\begin{array}{l}1864 \\
(15.3 \%)\end{array}$ & $\begin{array}{l}1970 \\
(16.1 \%)\end{array}$ & $\begin{array}{l}256 \\
(11.6 \%)\end{array}$ & $\begin{array}{l}289 \\
(13 \%)\end{array}$ & $\begin{array}{l}2472 \\
(11.9 \%)\end{array}$ & $\begin{array}{l}2768 \\
(13.4 \%)\end{array}$ & $\begin{array}{l}2147 \\
(13.1 \%)\end{array}$ & $\begin{array}{l}2283 \\
(14.0 \%)\end{array}$ & $\begin{array}{l}60 \\
(22.1 \%)\end{array}$ & $\begin{array}{l}67 \\
(24.7 \%)\end{array}$ \\
\hline 20 to 40 & $\begin{array}{l}6579 \\
(18.0 \%)\end{array}$ & $\begin{array}{l}7039 \\
(19.3 \%)\end{array}$ & $\begin{array}{l}2156 \\
(17.7 \%)\end{array}$ & $\begin{array}{l}2288 \\
(17.9 \%)\end{array}$ & $\begin{array}{l}347 \\
(15.7 \%)\end{array}$ & $\begin{array}{l}331 \\
(14.9 \%)\end{array}$ & $\begin{array}{l}3290 \\
(15.9 \%\end{array}$ & $\begin{array}{l}3613 \\
(17.4 \%)\end{array}$ & $\begin{array}{l}2662 \\
(16.3 \%)\end{array}$ & $\begin{array}{l}2961 \\
(18.1 \%)\end{array}$ & $\begin{array}{l}63 \\
(23.2 \%)\end{array}$ & $\begin{array}{l}58 \\
(21.4 \%)\end{array}$ \\
\hline 40 to 60 & $\begin{array}{l}8354 \\
(22.9 \%)\end{array}$ & $\begin{array}{l}7715 \\
(21.2 \%)\end{array}$ & $\begin{array}{l}2848 \\
(23.4 \%)\end{array}$ & $\begin{array}{l}2708 \\
(22.3 \%)\end{array}$ & $\begin{array}{l}611 \\
(27.5 \%)\end{array}$ & $\begin{array}{l}575 \\
(25.9 \%)\end{array}$ & $\begin{array}{l}5486 \\
(26.4 \%)\end{array}$ & $\begin{array}{l}4913 \\
(23.7 \%)\end{array}$ & $\begin{array}{l}4097 \\
(25.0 \%)\end{array}$ & $\begin{array}{l}3857 \\
(23.6 \%)\end{array}$ & $\begin{array}{l}45 \\
(16.6 \%)\end{array}$ & $\begin{array}{l}65 \\
(24.0 \%)\end{array}$ \\
\hline 60 to 80 & $\begin{array}{l}8065 \\
(22.2 \%)\end{array}$ & $\begin{array}{l}7491 \\
(20.5 \%)\end{array}$ & $\begin{array}{l}2784 \\
(22.8 \%)\end{array}$ & $\begin{array}{l}2577 \\
(21.2 \%)\end{array}$ & $\begin{array}{l}584 \\
(26.3 \%)\end{array}$ & $\begin{array}{l}562 \\
(25.3 \%)\end{array}$ & $\begin{array}{l}5137 \\
(24.7 \%)\end{array}$ & $\begin{array}{l}4973 \\
(23.9 \%)\end{array}$ & $\begin{array}{l}3963 \\
(24.2 \%)\end{array}$ & $\begin{array}{l}3829 \\
(23.4 \%)\end{array}$ & $\begin{array}{l}47 \\
(17.4 \%)\end{array}$ & $\begin{array}{l}29 \\
(10.7 \%)\end{array}$ \\
\hline 80 to 100 & $\begin{array}{l}7533 \\
(20.7 \%)\end{array}$ & $\begin{array}{l}7589 \\
(20.8 \%)\end{array}$ & $\begin{array}{l}2483 \\
(20.3 \%)\end{array}$ & $\begin{array}{l}2559 \\
(21.0 \%)\end{array}$ & $\begin{array}{l}411 \\
(18.5 \%)\end{array}$ & $\begin{array}{l}440 \\
(19.8 \%)\end{array}$ & $\begin{array}{l}4281 \\
(20.7 \%)\end{array}$ & $\begin{array}{l}4345 \\
(20.9 \%)\end{array}$ & $\begin{array}{l}3433 \\
(21.0 \%)\end{array}$ & $\begin{array}{l}3342 \\
(20.4 \%)\end{array}$ & $\begin{array}{l}56 \\
(20.7 \%)\end{array}$ & $\begin{array}{l}31 \\
(18.8 \%)\end{array}$ \\
\hline Not collected & $\begin{array}{l}162 \\
(0.4 \%)\end{array}$ & $\begin{array}{l}314 \\
(0.9 \%)\end{array}$ & 55 (0.5\% & $\begin{array}{l}88 \\
(0.7 \%)\end{array}$ & $\begin{array}{l}13 \\
(0.6 \%)\end{array}$ & 25 (1.1\%) & 98 (0.5\%) & $152(0.7 \%)$ & 80 (0.5\%) & $110(0.7 \%)$ & $0(0.0 \%)$ & $1(0.4 \%)$ \\
\hline \multicolumn{13}{|l|}{ CHD } \\
\hline Yes & $\mathrm{N} / \mathrm{A}$ & $\mathrm{N} / \mathrm{A}$ & $\begin{array}{l}10473 \\
(85.9 \%)\end{array}$ & $\begin{array}{l}10509 \\
(86.2 \%)\end{array}$ & $\begin{array}{l}1322 \\
(59.5 \%)\end{array}$ & $\begin{array}{l}1326 \\
(59.7 \%)\end{array}$ & $\begin{array}{l}16053 \\
(77.3 \%)\end{array}$ & $\begin{array}{l}16114 \\
(77.6 \%)\end{array}$ & $\begin{array}{l}13213 \\
(80.7 \%)\end{array}$ & $\begin{array}{l}13293 \\
(81.1 \%)\end{array}$ & $\begin{array}{l}113 \\
(41.7 \%)\end{array}$ & $\begin{array}{l}112 \\
(41.3 \%)\end{array}$ \\
\hline \multicolumn{13}{|l|}{ CKD } \\
\hline Yes & $\begin{array}{l}14978 \\
(41.2 \%)\end{array}$ & $\begin{array}{l}14929 \\
(41.0 \%)\end{array}$ & $\mathrm{N} / \mathrm{A}$ & $\mathrm{N} / \mathrm{A}$ & $\begin{array}{l}661 \\
(29.7 \%)\end{array}$ & $\begin{array}{l}658 \\
(29.6 \%)\end{array}$ & $\begin{array}{l}6429 \\
(31.0 \%)\end{array}$ & $\begin{array}{l}6357 \\
(30.6 \%)\end{array}$ & $\begin{array}{l}7771 \\
(47.4 \%)\end{array}$ & $\begin{array}{l}7824 \\
(47.8 \%)\end{array}$ & $\begin{array}{l}90 \\
(33.2 \%)\end{array}$ & $\begin{array}{l}86 \\
(31.7 \%)\end{array}$ \\
\hline \multicolumn{13}{|l|}{ CLD } \\
\hline Yes & $\begin{array}{l}2348 \\
(6.5 \%)\end{array}$ & $\begin{array}{l}2207 \\
(6.1 \%)\end{array}$ & $\begin{array}{l}853 \\
(7.0 \%)\end{array}$ & $\begin{array}{l}795 \\
\text { (6.5\%) }\end{array}$ & $\mathrm{N} / \mathrm{A}$ & $\mathrm{N} / \mathrm{A}$ & $\begin{array}{l}1487 \\
(7.2 \%)\end{array}$ & $\begin{array}{l}1351 \\
(6.5 \%)\end{array}$ & $\begin{array}{l}1538 \\
(9.4 \%)\end{array}$ & $\begin{array}{l}1442 \\
(8.8 \%)\end{array}$ & $\begin{array}{l}25 \\
(9.2 \%)\end{array}$ & $20(7.4 \%)$ \\
\hline \multicolumn{13}{|l|}{ CRD } \\
\hline Yes & $\begin{array}{l}18363 \\
(50.5 \%)\end{array}$ & $\begin{array}{l}18351 \\
(50.4 \%)\end{array}$ & $\begin{array}{l}5762 \\
(47.3 \%)\end{array}$ & $\begin{array}{l}5761 \\
(47.3 \%)\end{array}$ & $\begin{array}{l}1042 \\
(46.9 \%)\end{array}$ & $\begin{array}{l}1049 \\
(47.2 \%)\end{array}$ & N/A & N/A & $\begin{array}{l}7833 \\
(47.8 \%)\end{array}$ & $\begin{array}{l}7788 \\
(47.5 \%)\end{array}$ & $\begin{array}{l}97 \\
(35.8 \%)\end{array}$ & $\begin{array}{l}101 \\
(37.3 \%)\end{array}$ \\
\hline \multicolumn{13}{|l|}{ Diabetes } \\
\hline Yes & $\begin{array}{l}11849 \\
(32.6 \%)\end{array}$ & $\begin{array}{l}11779 \\
(32.4 \%)\end{array}$ & $\begin{array}{l}5094 \\
(41.8 \%)\end{array}$ & $\begin{array}{l}5159 \\
(42.3 \%)\end{array}$ & $\begin{array}{l}813 \\
(36.6 \%)\end{array}$ & $\begin{array}{l}817 \\
(36.8 \%)\end{array}$ & $\begin{array}{l}5791 \\
(27.9 \%)\end{array}$ & $\begin{array}{l}5528 \\
(26.6 \%)\end{array}$ & $\mathrm{N} / \mathrm{A}$ & $N / A$ & $\begin{array}{l}62 \\
(22.9 \%)\end{array}$ & $\begin{array}{l}81 \\
(29.9 \%)\end{array}$ \\
\hline
\end{tabular}




\begin{tabular}{|c|c|c|c|c|c|c|c|c|c|c|c|c|}
\hline \multirow[b]{2}{*}{ Demographics } & \multicolumn{2}{|l|}{ CHD } & \multicolumn{2}{|l|}{ CKD } & \multicolumn{2}{|l|}{ CLD } & \multicolumn{2}{|l|}{ CRD } & \multicolumn{2}{|l|}{ Diabetes } & \multicolumn{2}{|c|}{ Post-BMT } \\
\hline & CAP & $\begin{array}{l}\text { non- } \\
\text { CAP }\end{array}$ & CAP & $\begin{array}{l}\text { non- } \\
\text { CAP }\end{array}$ & CAP & non-CAP & CAP & non-CAP & CAP & non-CAP & CAP & non-CAP \\
\hline \multicolumn{13}{|l|}{ post-BMT } \\
\hline Yes & $\begin{array}{l}86 \\
(0.2 \%)\end{array}$ & $\begin{array}{l}51 \\
(0.1 \%)\end{array}$ & $\begin{array}{l}85 \\
(0.7 \%)\end{array}$ & $\begin{array}{l}76 \\
(0.6 \%)\end{array}$ & $\begin{array}{l}15 \\
(0.7 \%)\end{array}$ & $7(0.3 \%)$ & $61(0.3 \%)$ & 35 (0.2\%) & $88(0.5 \%)$ & $64(0.4 \%)$ & $\mathrm{N} / \mathrm{A}$ & N/A \\
\hline \multicolumn{13}{|l|}{$\begin{array}{l}\text { Mean } \\
\text { admissions } \\
2012 / 2013\end{array}$} \\
\hline Elective (mean) & 4.2 & 3.6 & 9.3 & 7.6 & 4.5 & 3.9 & 2.9 & 2.5 & 5 & 3.6 & 18.3 & 16.3 \\
\hline $\begin{array}{l}\text { Non-elective } \\
\text { (mean) }\end{array}$ & 2.2 & 2.1 & 2.5 & 2.4 & 3.1 & 3.1 & 2.3 & 2.2 & 2.2 & 2.2 & 3.2 & 3.0 \\
\hline Total (mean) & 3.7 & 3.4 & 6.3 & 5.5 & 5.3 & 5 & 3.3 & 3.1 & 4.2 & 3.5 & 20.0 & 17.3 \\
\hline
\end{tabular}

BMT, bone marrow transplant ; CAP, community-acquired pneumonia ; CHD, chronic heart disease ; CKD, chronic kidney disease ; CLD, chronic liver disease ; CRD, chronic respiratory disease ; N/A, Not Applicable.

comorbidities included, which is consistent with previous findings on the impact of underlying comorbidities and the risk of invasive pneumococcal disease (IPD). ${ }^{19}$

Our study also shows that patients with these comorbidities who are diagnosed with hospitalised CAP subsequently cost more money to treat over the 3-year period following the initial episode of CAP compared with matched controls who did not have an episode of pneumonia. The costs varied substantially by comorbidity, with the mean difference ranging between $£ 6000$ over 3 years for CHD patients to over $£ 11000$ for CRD patients. However, for CKD patients, this trend was inconsistent in 2014/2015, when those with hospitalised CAP cost less than their matched controls. A similar but not significant observation was also made for diabetic patients in 2015/2016. One possible explanation is that hospitalisation with CAP provides an opportunity to review the treatment for an individual's underlying condition. This review subsequently leads to an improvement in treatment of the underlying condition, thereby averting future related hospital costs and admissions related to their underlying condition. This might be specific to CKD and diabetes and the way in which they are managed. We chose to calculate the difference in cost using HRGs which provides insight to the cost that hospitals would have received for treating these patients, but it does not reflect the full picture of costs and notably is not able to capture costs in the community following discharge. A separate specific cost analysis of hospitalised pneumonia would be needed to more accurately determine a more accurate cost.

Our study found that patients with certain underlying comorbidities have a significantly higher likelihood of in-hospital mortality following an episode of hospitalised CAP. The ORs were $>4$ for all six comorbidities which underlines the importance of measures to prevent episodes of hospitalised pneumonia in patients with comorbidities.

The key findings of this study suggest that following an episode of CAP, adults with underlying comorbidities are subsequently associated with increased healthcare resource utilisation and are at increased risk of mortality for an extended period. An episode of hospitalised CAP is therefore likely to have a prolonged adverse effect on the subsequent health of adults with underlying comorbidities, which supports considering pneumonia as a chronic rather than an acute condition. ${ }^{21}$ An episode of CAP in adults with underlying comorbidities appears likely to leave them particularly prone to long-term adverse health consequences. ${ }^{22}$ While this is the first time insights in this context have been obtained using a population of UK adults with underlying comorbidities specifically, similar research undertaken outside the UK has previously highlighted that adults may be left with a compromised health status following an episode of hospitalised CAP. A recent systematic review and meta-analysis reported an increased risk of myocardial infarction, heart failure, dysrhythmias and stroke after CAP, which is maximal in the acute phase but persists long-term after resolution of the pneumonia.$^{23}$ The finding that there is an increased likelihood of mortality following an episode of hospitalised CAP is reflected by a study in Dutch adults which suggested long-term mortality was higher in those with an underlying comorbidity following an episode of IPD or pneumonia. ${ }^{24}$ A possible explanation for this is that an episode of hospitalised CAP can compromise the long-term health status of patients with underlying comorbidities.

This study suggests it is not appropriate to continue to consider an episode of hospitalised CAP as a discreet event for patients with comorbidities. Rather, the impact of hospitalised CAP should be considered over a longer period accounting for the impact on both the patient and the healthcare system. Furthermore, it is important to consider the personal impact on quality of life for these patients and their families along with some of the often unreported consequences of CAP, including wider societal implications such as time off work. ${ }^{25}$

The increasing numbers of patients with comorbidities and elderly patients hospitalised with CAP will consume a 


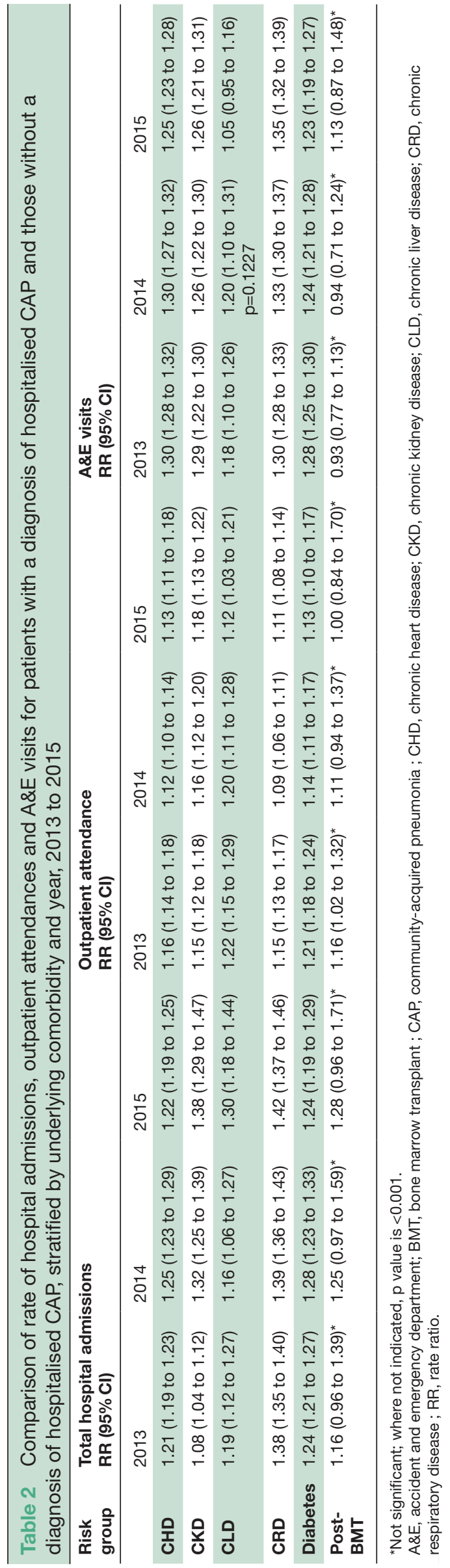
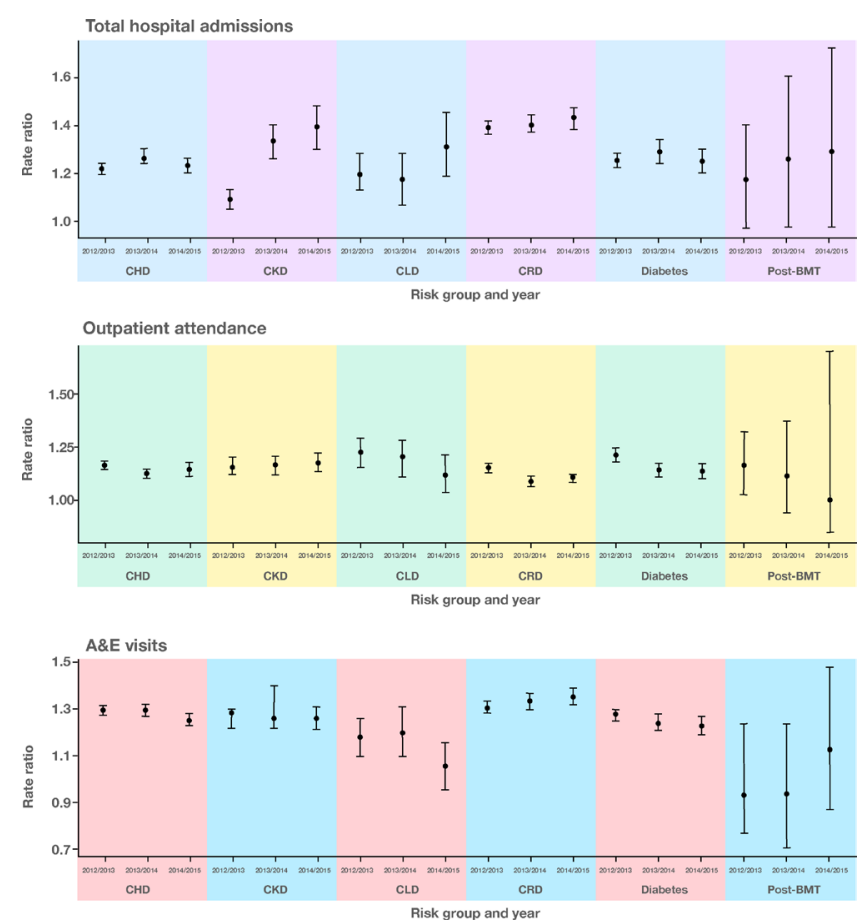

Figure 2 Comparison of rate of hospital admissions, outpatient attendances and $A \& E$ visits for patients with a diagnosis of hospitalised CAP and those without a diagnosis of hospitalised CAP, stratified by underlying co-morbidity and year. A\&E, accident and emergency department; BMT, bone marrow transplant; CAP, community-acquired pneumonia; $\mathrm{CHD}$, chronic heart disease; CKD, chronic kidney disease; CLD, chronic liver disease; $\mathrm{CRD}$, chronic respiratory disease.

large percentage of health resources in the future. ${ }^{26}$ Our data suggest that those with underlying conditions continue to be at an increased risk of hospitalised CAP and its associated consequences. Since the risk varies by comorbidity, it should be possible to target these comorbidity groups with appropriate preventative measures including influenza and pneumococcal immunisations.

This study reflects the UK healthcare system, the NHS, and its findings are therefore mainly of relevance for the UK, but may nevertheless be of interest for other healthcare systems.

CAP is a significant contributor to winter pressures that the NHS faces each year. Strategies to prevent pneumonia, including smoking cessation, pneumococcal vaccination and seasonal influenza vaccination, are important. Clinicians are advised to provide patients with written advice on pneumonia recovery when they are discharged from hospital. It is therefore disappointing that the most recent British Thoracic Society audit of adult CAP found that only $5.8 \%$ of participating hospitals routinely provided written advice to pneumonia patients when discharged from hospital. ${ }^{27}$

\section{Strengths and weaknesses of the study}

This study used HES data which has acknowledged limitations, particularly regarding quality and consistency of 
Table 3 Mean difference in hospital healthcare costs for patients in each comorbidity who developed hospitalised CAP versus those who did not throughout the 3-year study

\begin{tabular}{|c|c|c|c|c|c|c|}
\hline \multicolumn{7}{|c|}{ Hospital healthcare resource costs $(£)$ : mean difference $(95 \% \mathrm{Cl})$} \\
\hline & CHD & CKD & CLD & CRD & Diabetes & Post-BMT \\
\hline $\begin{array}{l}\text { Total admissions } \\
\text { 2013/2014 }\end{array}$ & $\begin{array}{l}4666 \text { (4542; } \\
4790)\end{array}$ & $\begin{array}{l}4958(4725 \\
5192)\end{array}$ & $\begin{array}{l}5693 \text { (5082; } \\
6305)\end{array}$ & $5264(5098 ; 5431)$ & $\begin{array}{l}1115(869 ; \\
1361)\end{array}$ & $\begin{array}{l}8444(6026 ; 10 \\
862)\end{array}$ \\
\hline $\begin{array}{l}\text { Total admissions } \\
2014 / 2015\end{array}$ & $\begin{array}{l}2679(2533 ; \\
2824)\end{array}$ & $\begin{array}{l}-1,916(-2295 \\
-1537)\end{array}$ & $\begin{array}{l}10774(9633 ; \\
11915)\end{array}$ & $\begin{array}{l}10947(10611 ; 11 \\
283)\end{array}$ & $\begin{array}{l}2675(2451 ; \\
2899)\end{array}$ & $\begin{array}{l}8030(3961 ; 12 \\
099)\end{array}$ \\
\hline $\begin{array}{l}\text { Total admissions } \\
2015 / 2016\end{array}$ & $\begin{array}{l}2056 \text { (1907; } \\
2206)\end{array}$ & $\begin{array}{l}2181(1894 ; \\
2468)\end{array}$ & $\begin{array}{l}1664(992 ; \\
2337)\end{array}$ & $2815(2616 ; 3015)$ & $\begin{array}{l}-1,692 \text { (-2020; } \\
1364)\end{array}$ & $\begin{array}{l}2010(-319 \\
4341)\end{array}$ \\
\hline $\begin{array}{l}\text { Total admissions } \\
2013 / 2014 \text { to } \\
2015 / 2016\end{array}$ & $\begin{array}{l}6103(5930 ; \\
6275)\end{array}$ & $\begin{array}{l}3800(3436 ; \\
4164)\end{array}$ & $\begin{array}{l}10858(9712 \\
12004)\end{array}$ & $\begin{array}{l}11167(10847 ; 11 \\
486)\end{array}$ & $\begin{array}{l}1907(1573 ; \\
2240)\end{array}$ & $\begin{array}{l}9274(4968 ; 13 \\
580)\end{array}$ \\
\hline
\end{tabular}

BMT, bone marrow transplant; CAP, community-acquired pneumonia ; CHD, chronic heart disease ; CKD, chronic kidney disease; CLD, chronic liver disease; CRD, chronic respiratory disease.

coding for pneumonia ${ }^{28} 29$ and potential errors of omission and commission of underlying comorbidities. The most recent national audit of hospitalised cases of CAP, conducted on behalf of the British Thoracic Society, ${ }^{27}$ compared prospectively identified pneumonia cases with HES data. The accuracy of a diagnosis of CAP at the national level varied widely between 124 participating hospitals. The median accuracy across all participating institutions was $65.6 \%$ (IQR $52.8 \%$ to $79.3 \%{ }^{27}$ The most common reason for exclusion of the diagnosis of CAP was the absence of new radiographic changes on chest $\mathrm{X}$-ray. It is therefore possible that some admissions for 'pneumonia' may in fact have been as a result of other conditions, including heart failure or decompensated underlying comorbidity. However, coding accuracy in HES has improved ever since the roll-out of financial incentives that are based on diagnosis and procedure codes. $^{30}$ Additionally, because of further reporting

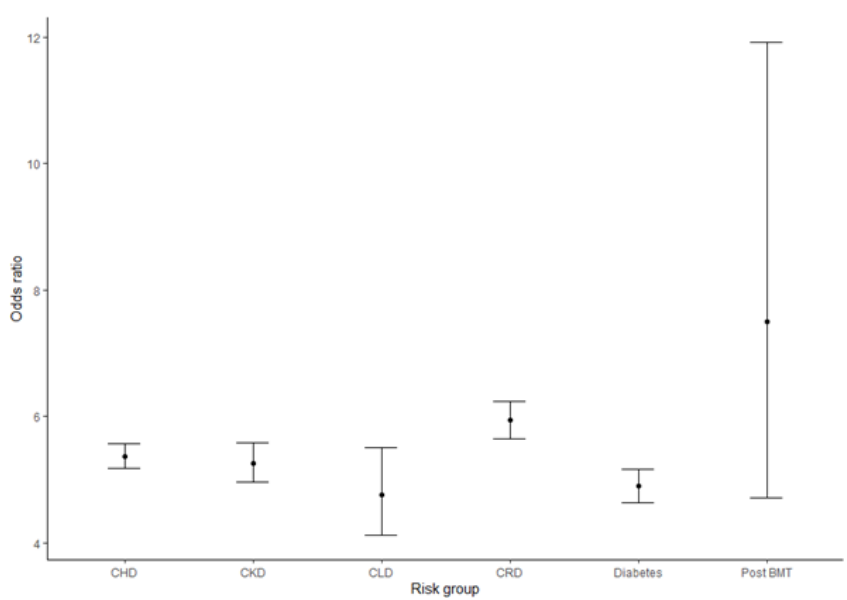

Figure 3 Adjusted ORs for mortality in each clinical risk group for those who developed hospitalised CAP compared with those who did not (online supplemental table 2). BMT, bone marrow transplant; CAP, communityacquired pneumonia; CHD, chronic heart disease; CKD, chronic kidney disease; CLD, chronic liver disease; CRD, chronic respiratory disease. requirements in the NHS, coding completeness has increased substantially. ${ }^{17} 20$ HES continues to be used in multiple studies for studying disease epidemiology and healthcare resource use in the NHS. ${ }^{1720}$ We chose to interrogate HES from financial year 2012/2013 when data reliability improved, following the introduction of payment by results. ${ }^{30}$

Due to the nature of coding in HES, it was not possible to fully differentiate between hospitalised CAP and HAP, although we did exclude all cases of pneumonia with onset occurring over 48 hours after admission. Patients admitted with a comorbidity diagnosis might be at an increased risk of developing HAP compared with those who have not been admitted with an underlying illness. Therefore, it is possible that presence of HAP within the data set may have resulted in overascertainment for all the outcomes measured.

Since we included patients whose comorbidity was coded in either the primary or secondary position, it is probable that a large proportion of patients will have multiple comorbidities. ${ }^{26}$ The risk of developing CAP increases when patients have several risk factors, a phenomenon known as 'risk stacking'. 1131 In order to correct for these confounders, we used PSM to compare the outcome variables between the two categories. ${ }^{32}$ The propensity scoring method has been used in other HES and CAP studies. ${ }^{83}$ We have not assessed the effect of multiple comorbidities in this study, but it is likely that the healthcare costs incurred, and in-hospital mortality would be elevated in patients with multiple risk factors. In a study of the impact of risk stacking on mortality from pneumococcal infections in adults, each additional risk factor increased the risk of mortality by $55 \% .{ }^{34} \mathrm{HES}$ data does not include data on other known risk factors for CAP, for example, smoking, alcohol abuse and use of proton pump inhibitors. It is therefore unclear whether these additional risk factors or a worsening clinical condition rather than an episode of hospitalised CAP are predictors of a worse outcome. A prospective study would be needed to establish the relative importance of these factors. 
Frailty increases the likelihood of hospitalisation with CAP. ${ }^{35}$ For example, in one study using the FRAIL index ${ }^{36}$ (FRAIL is a five-item scale of fatigue, resistance, ambulation, illnesses and weight loss) a score $>3$ was associated with an increase in duration of stay in hospital and an increase in in-hospital mortality. ${ }^{37}$ Since prevalidated frailty scores such as the FRAIL index are not recorded in the HES database, we were unable to adjust for frailty. Another potential confounder is chronic disease severity. Based on the data extracted as part of this study, it was not possible to determine the contribution of the chronic disease severity or the degree of frailty to the clinical and financial burden consequent on an episode of hospitalised CAP. ${ }^{38}$ It is unclear whether an episode of CAP requiring hospitalisation per se alters the course of a chronic disease, or is in fact a marker of worsening disease severity or increasing frailty resulting in a worse outcome. Millett $e$ a l $^{18}$ investigated the factors associated with hospitalisation for CAP among adults aged $\geq 65$ years in England, using linked primary and secondary care data sets; the Clinical Practice Research Datalink ${ }^{39}$ and HES. After adjusting for age, sex and year, they found frailty factors (inability to self-care, mobility problems, tiredness and a history of falling) did not increase the risk of hospitalisation for CAP. The authors did note that frailty factors and smoking were suboptimally recorded by general practitioners, preventing a full assessment of the role of these factors and highlighting the need for better data on these parameters.

Finally, it was not possible to account for loss of patients from the study due to mortality outside of the hospital setting. The HES data warehouse only includes records of patients' contacts with hospitals in England. The available data would therefore only reflect death in hospital during an admission, rather than longer-term mortality. The increased likelihood of dying for patients who have had an episode of hospitalised CAP presented in this analysis may therefore be an underestimate. By linking the HES database to Office for National Statistics central mortality data, it would be possible to estimate mortality without restricting the analysis to those patients who died in hospital.

\section{Meaning of the study: implications for clinicians and policymakers}

This study suggests the adverse effect of an episode of hospitalised CAP for those with underlying comorbidities, both for the individual patient and for the NHS. Quantification of these effects in patients with underlying comorbidities could be useful for policy makers when deciding about preventative measures.

\section{Unanswered questions and future research}

This study examined the impact of an episode of hospitalised CAP on patients with at least one of six selected underlying comorbidities over a period of 3 years. The longer-term duration of the impact of an episode of hospitalised CAP on healthcare utilisation and mortality for patients with the six comorbidities studied has not been determined. The study did not include patients with other comorbidities, including immunosuppression and functional asplenia. Future research could address these unanswered questions.

\section{CONCLUSION}

Following an admission to hospital for CAP, the impact on the patient and the healthcare system is significant and can continue for at least 3 years following the initial diagnosis. While there is variation by comorbidity, the risk of admission to hospital is significantly increased for at least 3 years after the episode of CAP, with increased pressure on hospital beds and also increased hospital costs. Furthermore, the likelihood of mortality was considerably raised in all comorbidities studied. This highlights the importance of prevention of CAP in these patient populations.

Acknowledgements The authors gratefully acknowledge the input from $\mathrm{K}$ Kishore of Health iQ Ltd for help with the design of the study, provision of the data and ongoing support.

Contributors JC, DJ, JDC, QJ, AV, HM and MS for study conception and design; APJR for data acquisition; QJ, AJPR and AV for statistical analysis; JC, MS, DJ and AV drafted the initial versions of article; all authors contributed to data interpretation, and read, commented on and approved the final version.

Funding This research was sponsored by Pfizer UK Ltd. Pfizer provided funding for the following: Hospital Episode Statistics (HES) data processing and analysis by Health iQ Ltd under an National Health Service digital re-use agreement and journal publication charges.

Competing interests All authors have completed the International Committee of Medical Journal Editors uniform disclosure form at www.icmje.org/coi_disclosure. pdf and declare the following: JDC has received research grant support from AstraZeneca, Pfizer, GlaxoSmithKline, Boehringer Ingelheim and Bayer Healthcare and has participated in advisory boards or lectures for Griffols, AstraZeneca, Pfizer, Napp, Boehringer Ingelheim and Bayer Healthcare. He also received remuneration from Pfizer for services as a member of the Steering Committee for this study. MS has received personal fees from GSK, Pfizer, AstraZeneca and Sanofi Pasteur as a speaker at international meetings and as a member of advisory boards (outside the scope of the submitted work). She has also worked as a contractor for Pfizer and received remuneration from Pfizer for services as a member of the Steering Committee for this study. JC, DJ, QJ, AV, GE and HM are full-time employees and shareholders of Pfizer; no other relationships or activities that could appear to have influenced the submitted work. APJR reports other from Health $\mathrm{i} Q$ and grants from Pfizer, outside the submitted work; and at the present time, I am providing consultancy work to Health iQ Ltd (UK), which works with clients across the life sciences industry.

Patient and public involvement Patients and/or the public were not involved in the design, or conduct, or reporting, or dissemination plans of this research.

Patient consent for publication Not required.

Provenance and peer review Not commissioned; internally peer-reviewed.

Data availability statement Data are available upon reasonable request from corresponding author.

Open access This is an open access article distributed in accordance with the Creative Commons Attribution Non Commercial (CC BY-NC 4.0) license, which permits others to distribute, remix, adapt, build upon this work non-commercially, and license their derivative works on different terms, provided the original work is properly cited, appropriate credit is given, any changes made indicated, and the use is non-commercial. See: http://creativecommons.org/licenses/by-nc/4.0/.

\section{REFERENCES}

1 Chalmers J, Campling J, Ellsbury G, et al. Community-Acquired pneumonia in the United Kingdom: a call to action. Pneumonia 2017;9:15. 
2 Lim WS, Baudouin SV, George RC, et al. BTS guidelines for the management of community acquired pneumonia in adults: update 2009. Thorax 2009;64 Suppl 3:iii1-55.

3 Chalmers JD, Mandal P, Singanayagam A, et al. Severity assessment tools to guide ICU admission in community-acquired pneumonia: systematic review and meta-analysis. Intensive Care Med 2011;37:1409-20.

4 van Hoek AJ, Miller E. Cost-Effectiveness of vaccinating immunocompetent $\geq 65$ year olds with the 13 -Valent pneumococcal conjugate vaccine in England. PLOS One 2016;11:e0149540.

5 Mangen M-JJ, Huijts SM, Bonten MJM, et al. The impact of community-acquired pneumonia on the health-related quality-of-life in elderly. BMC Infect Dis 2017;17:208.

6 Andrade LF, Saba G, Ricard J-D, et al. Health related quality of life in patients with community-acquired pneumococcal pneumonia in France. Health Qual Life Outcomes 2018;16:28.

7 Rae N, Finch S, Chalmers JD. Cardiovascular disease as a complication of community-acquired pneumonia. Curr Opin Pulm Med 2016;22:212-8.

8 Rozenbaum MH, van Hoek AJ, Fleming D, et al. Vaccination of risk groups in England using the 13 valent pneumococcal conjugate vaccine: economic analysis. BMJ 2012;345:e6879.

9 van Hoek AJ, Andrews N, Waight PA, et al. The effect of underlying clinical conditions on the risk of developing invasive pneumococcal disease in England. J Infect 2012;65:17-24.

10 GOV.UK. Immunisation Against Infectious Diseases. In: Pneumococcal: the green book, chapter 25, 2018. https://www. gov.uk/government/publications/pneumococcal-the-green-bookchapter-25

11 Shea KM, Edelsberg J, Weycker D, et al. Rates of pneumococcal disease in adults with chronic medical conditions. Open Forum Infect Dis 2014;1:ofu024.

12 Choudhury G, Mandal P, Singanayagam A, et al. Seven-day antibiotic courses have similar efficacy to prolonged courses in severe community-acquired pneumonia--a propensity-adjusted analysis. Clin Microbiol Infect 2011;17:1852-8.

13 Masterton RG, Galloway A, French G, et al. Guidelines for the management of hospital-acquired pneumonia in the UK: report of the Working Party on hospital-acquired pneumonia of the British Society for antimicrobial chemotherapy. J Antimicrob Chemother 2008;62:5-34.

14 NHS-Choices. A simple guide to payment by results. gateway Ref: 18135. Available: https://assets.publishing.service.gov.uk/ government/uploads/system/uploads/attachment_data/file/213150/ PbR-Simple-Guide-FINAL.pdf

15 (PSSRU), PSRU. Hospital and community health services (HCHS) index, 2015. Available: http://www.pssru.ac.uk/project-pages/unitcosts/2015/index.php?file=sources-of-information

16 Charlson ME, Pompei P, Ales KL, et al. A new method of classifying prognostic comorbidity in longitudinal studies: development and validation. J Chronic Dis 1987;40:373-83.

17 Thorrington D, Andrews N, Stowe J, et al. Elucidating the impact of the pneumococcal conjugate vaccine programme on pneumonia, sepsis and otitis media hospital admissions in England using a composite control. BMC Med 2018;16:13.

18 Millett ERC, De Stavola BL, Quint JK, et al. Risk factors for hospital admission in the 28 days following a community-acquired pneumonia diagnosis in older adults, and their contribution to increasing hospitalisation rates over time: a cohort study. BMJ Open 2015;5:e008737.

19 van Hoek AJ, Andrews N, Waight PA, et al. The effect of underlying clinical conditions on the risk of developing invasive pneumococcal disease in England. $J$ Infect 2012;65:17-24.
20 Campling J, Jones D, Chalmers JD, et al. The impact of certain underlying comorbidities on the risk of developing hospitalised pneumonia in England. Pneumonia 2019;11:4.

21 Dela Cruz CS, Wunderink RG, Christiani DC, et al. Future research directions in pneumonia. NHLBI Working Group report. Am J Respir Crit Care Med 2018;198:256-63.

22 Wunderink RG, Waterer G. Advances in the causes and management of community acquired pneumonia in adults. BMJ 2017;358:j2471.

23 Tralhão A, Póvoa P. Cardiovascular events after community-acquired pneumonia: a global perspective with systematic review and metaanalysis of observational studies. J Clin Med 2020;9

24 Wagenvoort GHJ, Sanders EAM, de Melker HE, et al. LongTerm mortality after IPD and bacteremic versus non-bacteremic pneumococcal pneumonia. Vaccine 2017;35:1749-57.

25 Cafiero-Fonseca ET, Stawasz A, Johnson ST, et al. The full benefits of adult pneumococcal vaccination: a systematic review. PLoS One 2017;12:e0186903-e.

26 Welte T, Torres A, Nathwani D. Clinical and economic burden of community-acquired pneumonia among adults in Europe. Thorax 2012;67:71-9.

27 Lim WS LH. British Thoracic Society national audit report: adult community acquired pneumonia 2018-2019 national audit period: 1December 2018-31 January 2019 British Thoracic Society Reports; 2019: 1-13.

28 Daniel P, Bewick T, Welham S, et al. Adults miscoded and misdiagnosed as having pneumonia: results from the British Thoracic Society pneumonia audit. Thorax 2017;72:376-9.

29 Herbert A, Wijlaars L, Zylbersztejn A, et al. Data resource profile: Hospital episode statistics admitted patient care (HES APC). Int J Epidemiol 2017;46:1093-1093i.

30 Health Do. Health and social care act 2012 The Stationery Office; 2012.

31 Caliendo M, Kopeinig S. Some practical guidance for the implementation of propensity score matching. J Econ Surv 2008;22:31-72.

32 Rosenbaum PR, Rubin DB. The central role of the propensity score in observational studies for causal effects. Biometrika 1983;70:41-55.

33 Eckmann C, Wasserman M, Latif F, et al. Increased Hospital length of stay attributable to Clostridium difficile infection in patients with four co-morbidities: an analysis of hospital episode statistics in four European countries. Eur J Health Econ 2013;14:835-46.

34 Morton JB, Morrill HJ, LaPlante KL, et al. Risk stacking of pneumococcal vaccination indications increases mortality in unvaccinated adults with Streptococcus pneumoniae infections. Vaccine 2017;35:1692-7.

35 Torres OH, Muñoz J, Ruiz D, et al. Outcome predictors of pneumonia in elderly patients: importance of functional assessment. J Am Geriatr Soc 2004;52:1603-9.

36 Aprahamian I, Cezar NOC, Izbicki R, et al. Screening for frailty with the FRAIL scale: a comparison with the phenotype criteria. J Am Med Dir Assoc 2017;18:592-6.

37 Chong E, Ho E, Baldevarona-Llego J, et al. Frailty and Risk of Adverse Outcomes in Hospitalized Older Adults: A Comparison of Different Frailty Measures. J Am Med Dir Assoc 2017;18:638.e7-638. e11.

38 Millett ERC, Quint JK, Smeeth L, et al. Incidence of communityacquired lower respiratory tract infections and pneumonia among older adults in the United Kingdom: a population-based study. PLoS One 2013;8:e75131.

39 Sanz JC, Rodríguez-Avial I, Ríos E, et al. Recurrent pneumococcal invasive disease in the region of Madrid during a five-year period. Infection 2014;42:475-83. 